\title{
CULTURA COMO DIREITO FUNDAMENTAL: REGRAS E PRINCÍPIOS CULTURAIS
}

\author{
Gustavo Assed Ferreira ${ }^{1}$ \\ Andrei Rossi Mango ${ }^{2}$
}

\section{RESUMO}

O presente trabalho tem por escopo demonstrar como a Constituição Federal de 1988 trata o direito à cultura, e se os direitos culturais são caracterizados como direitos fundamentais. Para tanto, realiza-se uma identificação das principais regras atinentes à cultura no ordenamento jurídico constitucional, bem como procede ao estudo sobre sua natureza jurídica como direitos fundamentais. Por fim, determina-se os princípios culturais, próprios e peculiares ao tema da cultura, decorrentes de uma interpretação constitucional sistemática. Como resultado, constata-se que os direitos culturais integram o rol de direitos e garantias fundamentais. A metodologia de pesquisa adotada é teórica, bibliográfica e documental.

Palavras-Chave: Cultura; Direitos Culturais; Direitos Fundamentais; Princípios Culturais; Constituição Federal.

\section{CULTURE AS FUNDAMENTAL RIGHT: RULES AND CULTURAL PRINCIPLES}

\begin{abstract}
This paper aims to demonstrate how the Federal Constitution of 1988 treats the cultural rights, and whether cultural rights are characterized as fundamental rights. In order to achieve this, the main rules related to culture are identified in the constitutional legal order, as well it proceeds to the study of its legal nature as fundamental rights. Lastly, it determines the cultural principles, proper and peculiar to the theme, arising from a systematic constitutional interpretation. As result, it's verified that cultural rights belong to the list of fundamental rights and guarantees. The research methodology adopted is theoretical, bibliographical and documentary literature.
\end{abstract}

Keywords: Culture; Cultural Rights; Fundamental Rights; Cultural Principles; Federal Constitution.

\section{INTRODUÇÃO}

\footnotetext{
${ }^{1}$ Doutor pela Universidade Federal de Santa Catarina - UFSC. Livre-Docente pela Universidade de São Paulo USP. Professor Associado da Faculdade de Direito de Ribeirão Preto da Universidade de São Paulo FDRP/USP.

${ }^{2}$ Mestrando em Direito e Desenvolvimento pela Universidade de São Paulo - FDRP/USP. Pós-graduando Lato Sensu em Direito Público pelo Damásio Educacional - DeVry Brasil. Bacharel em Direito pela Universidade Federal de Uberlândia - FADIR/UFU.
} 
Ao longo do trabalho pretende-se abordar o tratamento jurídico presente na Constituição Federal de 1988 no que se refere à tutela dos direitos culturais. Ademais, também procura-se investigar se a legislação constitucional os atribui a natureza jurídica de direitos fundamentais. Constata-se, portanto, que o objetivo geral da pesquisa é investigar o arcabouço normativo constitucional sobre a proteção e acesso à cultura, realizando sua delimitação normativa, e explorando os princípios próprios dos direitos culturais.

Primeiramente, analisa-se a previsão normativa da cultura no direito positivo, ou seja, dos principais dispositivos legais patentes na Constituição Federal de 1988 que consolidam os direitos culturais, em especial destaca-se os artigos 215, 216 e 216-A. Também, neste tópico justifica-se a designação da Lei Maior como Constituição Cultural.

Em um segundo momento, procede-se à verificação dos direitos culturais como direitos fundamentais, tendo em vista que são equiparados aos demais direitos fundamentais previstos na Constituição Federal, tais como os direitos sociais e econômicos.

Por último, verifica-se os princípios próprios dos direitos culturais, para se evidenciar os valores culturais implícitos e explícitos no ordenamento constitucional brasileiro, além de desempenhar o papel legitimador desses direitos, e constatar sua harmonia com os demais princípios e garantias do Estado Democrático de Direito.

Trata-se, pois, de uma pesquisa teórica, que utiliza como marco teórico três autores atinentes ao tema dos direitos culturais, são eles: José Afonso da Silva, Francisco Humberto Cunha Filho, e Guilherme Rosa Varella. Quanto ao procedimento para a construção do raciocínio, fora realizado revisão bibliográfica (teses, dissertações e artigos científicos) e documental (Constituição Federal de 1988).

\section{PREVISÃO CONSTITUCIONAL DA CULTURA}

A Constituição Federal de 1988 trouxe uma considerável e extensa previsão do termo cultura em seu rol normativo constitucional. Essa constituição buscou não só ampliar os direitos individuais e coletivos, como também estabeleceu uma série de direitos fundamentais para os cidadãos a fim de concretizar a democracia.

O contexto democrático trouxe reflexos sobre a previsão constitucional da cultura e estabeleceu o que pode ser chamado de democracia cultural, isto é, não há a imposição de 
uma cultura oficial na Constituição de 1988, mas sim de um diálogo sobre o que vem a ser identificado como cultura nacional (BORGES, 2016, p. 251-253). A cultura a ser protegida pelo ordenamento jurídico constitucional é marcada por ser plural, comportando uma diversidade de conceitos, como o abarcado pela visão semiótica (semiótica da cultura) e a antropológica (antropologia cultural).

Dado esse fato, a Constituição Brasileira de 1988 também ficou conhecida como Constituição Cultural (CUNHA FILHO, 2011, p. 119), ou como coloca José Afonso da Silva, "Ordenação Constitucional da Cultura", uma vez que estabelece um extenso conjunto de normas jurídico-constitucionais (valores, princípios e normas) protetoras de valores referentes à cultura, com o objetivo de garantir seu acesso, a liberdade de criação, a difusão, a igualdade e o gozo dos bens culturais (VARELLA, 2013, p. 91).

Por sua vez, José Afonso da Silva (2001, p. 42-43) sistematiza os artigos presentes na Constituição Federal de 1988 que fazem referência ao termo cultura, são eles: artigo 5º, IX, XXVII, XXVIII, LXXIII e artigo 220, $\S \S 2^{\circ}$ e $3^{\circ}$ (liberdade de manifestação, direito individual, e direitos autorais); artigos 23, 24 e 30 (regras de distribuição de competência e cultura como objeto de ação popular); artigo 219 (como incentivo ao mercado interno, como viabilizador do desenvolvimento cultural); artigo 221 (princípio a serem atendidos na produção e programação das emissoras de rádio e televisão); artigo 227 (cultura como direito da criança e do adolescente); artigo 231 (índios e sua organização social como costumes, tradições, línguas, crenças, tradições e terras ocupadas para a manifestação cultural indígena); artigos 215 e 216 (objetos culturais de Direito e patrimônio cultural brasileiro).

Passa-se então para uma análise dos artigos 215 e 216, da Lei Maior de 1988. Esses artigos são os que mais se aproximam de uma visão semiótica, antropológica e pluralista do termo cultura. O artigo 215 apresenta uma norma de caráter impositivo, em que destina estabelecer o dever do Estado de garantir a cultura nacional pelo pleno exercício e pelo acesso às fontes culturais. Conforme observa-se abaixo:

Art. 215. O Estado garantirá a todos o pleno exercício dos direitos culturais e acesso às fontes da cultura nacional, e apoiará e incentivará a valorização e a difusão das manifestações culturais.

$\S 1^{\circ} \mathrm{O}$ Estado protegerá as manifestações das culturas populares, indígenas e afro-brasileiras, e das de outros grupos participantes do processo civilizatório nacional.

$2^{\circ}$ A lei disporá sobre a fixação de datas comemorativas de alta significação para os diferentes segmentos étnicos nacionais. 
$3^{\circ}$ A lei estabelecerá o Plano Nacional de Cultura, de duração plurianual, visando ao desenvolvimento cultural do País e à integração das ações do poder público que conduzem à:

I - defesa e valorização do patrimônio cultural brasileiro;

II - produção, promoção e difusão de bens culturais;

III - formação de pessoal qualificado para a gestão da cultura em suas múltiplas dimensões;

IV - democratização do acesso aos bens de cultura;

V - valorização da diversidade étnica e regional. (grifo nosso).

Como observado acima, tem-se que é dever do Estado, valorizar a cultura, garantir o exercício da cultura e difusão das manifestações culturais, bem como assegurar o acesso às fontes de cultura nacional. Esse dever advém dos princípios fundamentais do Estado Democrático de Direito, "que incluem a cidadania, a dignidade da pessoa humana, a construção de uma sociedade livre, justa e solidária, a garantia do desenvolvimento nacional, a erradicação da pobreza e da marginalização, a redução da desigualdade sociais e regionais e a promoção do bem de todos" (SALLES, 2014, p. 26-27).

$\mathrm{O}$ acesso à cultura, por sua vez, é meio para consubstanciar o direito de igualdade e de identidade individual $^{3}$, que tem por finalidade reafirmar os direitos de gozo das liberdades de manifestação do pensamento, e manifestação e exercício dos direitos políticos ${ }^{4}$, garantindo assim, os direitos sociais e a concretização dos direitos de solidariedade (SALLES, 2014, p. 27).

Nota-se, também, que apesar do artigo 215 não esgotar o conteúdo dos direitos culturais, ele estabelece os núcleos substantivos que o Estado Democrático de Direito (ou Estado de Cultura) deve promover, são eles: o acesso, apoio, o incentivo, a valorização e a difusão da cultura (VARELLA, 2013, p. 94). Ainda, por outro ângulo, os direitos culturais constitucionais podem ser enumerados, de maneira não exaustiva, através da divisão das categorias a seguir:

(a) Liberdade de expressão da atividade intelectual, artística e científica; (b) direito à criação cultural, compreendidas as criações

\footnotetext{
${ }^{3} \mathrm{O}$ direito de igualdade e identidade individual corresponde a garantia de igualdade de direitos que também se concretiza com o respeito à diferença cultural dos indivíduos inseridos na sociedade. Em que pese, essa diferença não deve ser interpretada como desigualdade de direitos entre os indivíduos, mas sim como o respeito à diferença cultural dos cidadãos que compõem a sociedade (a cultura que os identificam), incluindo-se, portanto, as culturas minoritárias e suas particularidades nessa perspectiva universal e multicultural que é a sociedade brasileira.

${ }^{4}$ Manifestações culturais são comumente carregadas de teor político e por isso se faz necessária a liberdade do exercício dos direitos políticos para se ter a garantia da livre manifestação cultural.
} 
artística, científicas e tecnológicas; (c) direito de acesso às fontes de cultura nacional; (d) direito de difusão das manifestações culturais; (e) direito de proteção às manifestações das culturas populares, indígenas e afro-brasileiras e de outros grupos participantes do processo civilizatório nacional; (f) direito-dever estatal de formação do patrimônio cultural brasileiro e de proteção dos bens de cultura - que, assim, ficam sujeitos a um regime jurídico especial, como forma de propriedade de interesse público. (SILVA, 2001, p. 51-52, grifo nosso).

Guilherme Rosa Varella (2013, p. 92-93), faz uma análise ao conteúdo e acepção da expressão "direitos culturais" verificada no artigo 215, trazida por José Afonso da Silva, que dispõe sobre a divisão desses direitos em duas dimensões, a de direito objetivo e a de direito subjetivo.

José Afonso da Silva chama a atenção para a "dupla dimensão" dos direitos resguardados. A primeira dimensão é a de direito objetivo, norma agendi, como obrigação do Estado que deve garantir o exercício destes direitos por todos. A segunda dimensão é a de direito subjetivo, facultas agendi, como faculdade de agir baseado nos direitos culturais. Assim há um direito objetivo da cultura, oriundo do conjunto de suas normas, e um direito subjetivo da cultura, advindo das "situações jurídicas em favor dos interessados", que lhe permitem lançar mão de sua faculdade subjetiva de exigir o cumprimento dos direitos pelo Estado. Se a este cabe garanti-los, aos cidadãos cabe reivindicá-los. Em outras palavras, "ao direito à cultura corresponde a obrigação correspectiva do Estado". (VARELLA, 2013, p. 92-93).

Salienta-se que essas classificações e conceituações de conteúdo dos direitos culturais não são unânimes entre os autores, dado que cada doutrinador apresenta sua própria classificação e abrangência do teor da palavra cultura, assim como sua incidência no texto normativo.

No que diz respeito à conceituação legalmente posta do que vem a ser cultura na Constituição Federal de 1988, cabe ressaltar que o próprio legislador se incumbiu de fazê-la no artigo 216, definindo o que é patrimônio cultural (de forma explícita) e cultura (de forma implícita) no âmbito jurídico nacional (CUNHA FILHO, 2004, p. 37). Denota-se que o legislador optou por atribuir um caráter mais universalista, ou seja, mais amplo. Conforme pode ser constatado:

Art. 216. Constituem patrimônio cultural brasileiro os bens de natureza material e imaterial, tomados individualmente ou em 
conjunto, portadores de referência à identidade, à ação, à memória dos diferentes grupos formadores da sociedade brasileira, nos quais se incluem:

I - as formas de expressão;

II - os modos de criar, fazer e viver;

III - as criações científicas, artísticas e tecnológicas;

IV - as obras, objetos, documentos, edificações e demais espaços destinados às manifestações artístico-culturais;

V - os conjuntos urbanos e sítios de valor histórico, paisagístico, artístico, arqueológico, paleontológico, ecológico e científico. [...]. (grifo nosso).

Observa-se que o artigo 216, caput e incisos, não só ampliou a abrangência da tutela da cultura nacional, sob a denominação do "patrimônio cultural brasileiro" (englobando os bens materiais e imateriais), como também o democratizou, abandonando a limitada expressão "patrimônio histórico e artístico nacional” presente na legislação infraconstitucional (SANTOS, 2011, p. 73).

No $\S 1^{\circ}$, do mesmo artigo, fora estipulado que o Poder Público em colaboração com a comunidade promoverá e protegerá o patrimônio cultural brasileiro através de inventários, registros, vigilância, tombamento e desapropriação, bem como por meio de outros institutos jurídicos que visem sua proteção.

O $\S 2^{\circ}$ determinou que fica à cargo da Administração Pública a gestão da documentação governamental e sua disponibilização para consulta de acordo com o princípio da legalidade ("na forma da lei").

Os $\S \S 3^{\circ}$ e $6^{\circ}$ tratam, respectivamente, do incentivo e fomento (financiamento) da cultura para a produção e o conhecimento de bens e valores culturais; e da possibilidade dos Estados e Distrito Federal em criar um fundo estadual de fomento à cultura, e vincular até o limite de cinco décimos por cento de sua receita tributária líquida para apoio e financiamento de programas e projetos culturais (SANTOS, 2011, p. 36).

Apesar deste último parágrafo (art. 216, §6, $\mathrm{CF} / 88$ ) ter sido incluído em 2003 pela Emenda Constitucional $n^{\circ} 42$, vários dos Estados só foram criar o fundo estadual de fomento à cultura (Sistema Estadual de Cultura) no período de 2013 até 2015 (SNC, 2017), tendo como um dos mais recentes o do Estado do Amapá, criado em 02 de março de 2017 (GUIMARÃES, 2017).

Além dos fundos estaduais, fora instituído o Sistema Nacional de Cultura, Política Nacional de Cultura e o Plano Nacional de Cultura pelo art. 216-A (CF/88), a fim de cumprir 
os preceitos constitucionais de financiamento da cultura nacional. Esse artigo foi incluído pela Emenda Constitucional no 71 de 2012 (EC no 71/2012), o qual promoveu uma descentralização administrativa e legislativa, conferindo mais autonomia aos Estados e criando um regime de colaboração, típico do federalismo norte-americano (TONET; BORDONI, 2016, p. 272).

Para uma melhor compreensão, expõe-se abaixo a inovação legislativa trazida pela EC $n^{\circ} 71 / 2012$ :

Art. 216-A. O Sistema Nacional de Cultura, organizado em regime de colaboração, de forma descentralizada e participativa, institui um processo de gestão e promoção conjunta de políticas públicas de cultura, democráticas e permanentes, pactuadas entre os entes da Federação e a sociedade, tendo por objetivo promover $o$ desenvolvimento humano, social e econômico com pleno exercício dos direitos culturais.

$\S 1^{\circ}$ O Sistema Nacional de Cultura fundamenta-se na política nacional de cultura e nas suas diretrizes, estabelecidas no Plano Nacional de Cultura, e rege-se pelos seguintes princípios:

I - diversidade das expressões culturais;

II - universalização do acesso aos bens e serviços culturais;

III - fomento à produção, difusão e circulação de conhecimento e bens culturais;

IV - cooperação entre os entes federados, os agentes públicos e privados atuantes na área cultural;

V - integração e interação na execução das políticas, programas, projetos e ações desenvolvidas;

VI - complementaridade nos papéis dos agentes culturais;

VII - transversalidade das políticas culturais;

VIII - autonomia dos entes federados e das instituições da sociedade civil;

IX - transparência e compartilhamento das informações;

$\mathrm{X}$ - democratização dos processos decisórios com participação e controle social;

XI - descentralização articulada e pactuada da gestão, dos recursos e das ações;

XII - ampliação progressiva dos recursos contidos nos orçamentos públicos para a cultura. (grifo nosso).

Visto os artigos que englobam a cultura no ordenamento jurídico constitucional, passase à análise da natureza jurídica deles, que são elevados e equiparados aos direitos fundamentais, mesmo não estando alocados com os demais direitos fundamentais no Capítulo II (Dos Direitos e Garantias Fundamentais), e sim no Capítulo III (Da Educação, da Cultura e 
do Desporto), Seção II (Da Cultura), da Constituição Federal de 1988. Sendo assim, cabe analisar o porquê de receberem essa atribuição.

\section{DIREITOS CULTURAIS COMO DIREITOS FUNDAMENTAIS}

Os direitos culturais recebem a atribuição de direitos fundamentais, mesmo não estando elencados conjuntamente com os demais direitos fundamentais previstos na Constituição Federal de 1988. Diversos autores reafirmam este entendimento, dentre eles estão José Afonso da Silva, que expõe que os direitos culturais são “direitos constitucionais atuais e fundamentais" (SILVA, 2001, p. 50); e Francisco Humberto Cunha Filho, que afirma que "os direitos culturais são fundamentais" (CUNHA FILHO, 2000, p. 43).

Os direitos fundamentais culturais, em uma interpretação stricto sensu, não devem ser entendidos de forma diferente dos demais direitos fundamentais, tendo em vista que são emparelhados com os demais direitos fundamentais, tais como os direitos econômicos, sociais, individuais, de liberdade, igualdade, entre outros. Além disso, em uma interpretação lato sensu, os direitos fundamentais podem ser compreendidos como a expressão da cultura humana em um estado constitucional (CUNHA FILHO, 2004, p. 36-37).

Em verdade, existem uma multiplicidade de terminologias que se referem ao âmbito dos direitos fundamentais. José Afonso da Silva, por exemplo, utiliza a denominação "direitos fundamentais do homem", em que expõe que os direitos fundamentais estabelecem as prerrogativas e instituições que assentam uma convivência digna, livre e igual para todas as pessoas (SILVA, 1999, p. 182). Para ele, os direitos fundamentais são direitos que determinam "situações jurídicas sem as quais a pessoa humana não se realiza, não convive e, às vezes, nem mesmo sobrevive" (SILVA, 1999, p. 183).

Na visão de Paulo Bonavides (2010, p. 562), o direito é considerado fundamental quando ele é essencial para a garantia de uma vida digna e para o exercício da cidadania, os quais estariam vinculados essencialmente com os princípios da liberdade e dignidade da pessoa humana (valores históricos e filosóficos).

Assim, pode-se entender que os direitos fundamentais são: aqueles que estão expostos de forma expressa na Constituição (formalmente constitucionais -os previstos no Título II da $\mathrm{CF} / 88$ ); aqueles de maior relevância dentro do ordenamento jurídico constitucional, tendo em 
vista seu caráter essencial na proteção da dignidade da pessoa humana, da cidadania e da liberdade (direitos fundamentais dispersos na CF/88); e aqueles que apesar de sua elevada importância, não estão previstos constitucionalmente (direitos fundamentais sem assento constitucional).

Também, salienta-se que os direitos fundamentais devem estar em consonância com os preceitos estabelecidos pelo sistema internacional de direito humanos. Aqui, converge-se na ideia de que os direitos fundamentais não se confundem com os direitos humanos, apesar de serem interdependentes e inter-relacionados no que toca a efetivação e concretização desses direitos, com o objetivo último de assegurar os direitos fundamentais sociais, econômicos e culturais (VARELLA, 2013, p. 61-62).

No entendimento de Francisco Humberto Cunha Filho (2000, p. 41), para que os direitos culturais se caracterizem como direitos fundamentais (recebam essa adjetivação), deve-se verificar os seguintes perfis:

1) devem estar inseridos no texto constitucional, preferencialmente no capítulo dos direitos e garantias fundamentais; 2) se não estiverem na Constituição, a sua existência deve ser tão significativa ao ponto de ser abraçada pelos princípios que informam o conjunto de direitos fundamentais, em seu aspecto material, dos quais sobressai-se o que sintetiza e justifica os demais, a multimencionada dignidade da pessoa humana. (CUNHA FILHO, 2000, p. 41).

O mesmo autor afirma que caso estejam inseridos em um desses perfis, o tratamento diferenciado que receberão serão o de:

1) proteção especial quanto à supressão do ordenamento; 2) a aplicabilidade imediata do ponto de vista de eficácia jurídica, bem como proteção contra a doutrina que advoga a existência de normas fundamentais programáticas, na seara dos direitos fundamentais; doutrina esta que, ao meu ver, usa tal argumentação como subterfúgio para não efetivar ou no mínimo procrastinar a prestação determinada pela Lei Maior. (CUNHA FILHO, 2000, p. 41-42).

A mera distância entre os artigos tratados como direitos fundamentais (art. $5^{\circ}, \mathrm{CF} / 88$ ) e os artigos que tratam sobre os direitos culturais (art. 215 a 216-A, CF/88) não são suficientes para determiná-los como não fundamentais. Mesmo porque, alguns dos incisos presentes no art. $5^{\circ}$ representam indiretamente os direitos culturais, tais como os incisos IX 
(liberdade de expressão artística), XXVII e XXVIII (direitos autorais e conexos), LXXIII (direito à proteção do patrimônio cultural).

O mínimo de razoabilidade constata o caráter fundamental desses direitos, uma vez que eles expressam aspectos subjetivos notórios de individualidade de uma pessoa ou de uma coletividade no que corresponde a identidade cultural e dignidade da pessoa humana.

Além disso, os direitos culturais se configuram como um fator de desenvolvimento humano essencial para a superação da pobreza (DONDERS; LAAKSONEN, 2011, p. 90), são imprescindíveis para o exercício dos demais direitos buscados pela sociedade, e visam a concretude dos diversos aspectos da dignidade da pessoa humana (VARELLA, 2013, p. 63).

Convergindo com os demais autores supra expostos, o presente trabalho reconhece que os direitos culturais recebem os status de direitos fundamentais, não só pela análise ex lege (realizada nos artigos 215 a 216-A da Constituição Federal de 1988), como também pelos princípios, implícitos e explícitos, que serão esmiuçados no tópico seguinte.

\section{PRINCÍPIOS CULTURAIS}

Antes de adentrar em uma enumeração dos princípios culturais implícitos e explícitos do ordenamento constitucional, é necessário expor no que consiste os princípios. Segundo Celso Antônio Bandeira de Mello (2008, p. 88-90), são os axiomas fundamentais albergados pelo sistema normativo, o qual desempenham o papel de informar e orientar sua interpretação, determinando as "noções radicais" que alicerçam todo o ordenamento.

Os princípios devem ser condizentes com as normas, e devem refletir os valores do ordenamento jurídico em que se inserem, dado que sua aplicação no caso concreto muitas vezes incorre no sopesamento de princípios, em que ambos são analisados com o mesmo grau de importância, aplicando o mais adequado para o determinado caso, sem que nenhum deles seja descartado.

Sucintamente, para determinar a distinção entre as espécies normativas, princípios e regras, cabe expor sobre a Teoria dos Direitos Fundamentais, de Robert Alexy (1993, p. 8185). Essa teoria determina que as regras estabelecem as condutas a serem observadas e respeitadas, e os princípios estabelecem os mandamentos possíveis a serem observados em determinado caso concreto, uma vez que são mais abertos à interpretação. 
Essa compreensão se faz necessária para que se tenha a máxima efetividade do direito vigente através da aplicação ou não dos princípios para a solução do caso concreto. Analogamente isso se aplica aos direitos culturais, o qual se faz necessário que os princípios sejam aplicados aos casos concretos, ou em eventuais conflitos entre princípios e regras jurídicas, que os primeiros prevaleçam. Isso porque as regras referentes aos direitos culturais ainda precisam ser melhor desenvolvidas, além de que não deixa de ser o papel dos princípios aferir a legitimidade de uma norma, estipulando sua submissão aos princípios regentes da dinâmica social (VARELLA, 2013, p. 100).

Os princípios possuem como característica basilar a possibilidade de converter a ética socialmente consagrada em direito estatal, levando-se em consideração a produção normativa de caráter valorativo. Novamente, de forma análoga à cultura, é necessário que se observe a relação atinente ao ordenamento jurídico vigente e o sistema de códigos referentes à cultura, integrando a interpretação e aplicação das normas culturais e a atuação do Estado na garantia desses direitos (VARELLA, 2013, p. 100-101).

Para Francisco Humberto Cunha Filho (2000, p. 43), “os princípios têm como características um alto grau de subjetividade e o fato de serem portadores dos valores éticos adotados pelo ordenamento jurídico". Observado essa conceituação, contata-se que os princípios e seus valores éticos estão presentes no ordenamento cultural brasileiro, no qual o autor supramencionado realiza uma comparação entre o direito positivado sobre cultura com a principiologia da Constituição, através de uma interpretação constitucional sistemática.

$\mathrm{Na}$ visão desse autor, estão presentes na Constituição Federal de 1988 diversos princípios culturais que sustentam a normatividade cultural nacional, são eles: o princípio do pluralismo cultural; o princípio da participação popular; o princípio da atuação estatal como suporte logístico; o princípio do respeito à memória coletiva; e o princípio da universalidade (2000, p. 44-52).

\subsection{Princípio do Pluralismo Cultural}

O princípio do pluralismo cultural estabelece que o Estado deve tratar as diferentes correntes de pensamento e manifestação cultural de forma igual e equiparadas, sem privilegiar qualquer uma delas ou estabelecer uma ordem de hierarquia, ou ainda, sem determinar alguma 
como oficial (CUNHA FILHO, 2000, p. 45-46). Se trata de um princípio que reconhece a existência e expressão de uma cultura plural e múltipla (inclusive a individual de cada cidadão) que se manifesta em uma sociedade comum, na formação da cultura nacional.

Esse princípio se manifesta em conformidade com o princípio democrático presente na Constituição Federal de 1988 (SANTOS, 2011, p. 38). Seu desrespeito afronta os preceitos estabelecidos pelo Estado Democrático de Direito, uma vez que seu objetivo maior é a harmonia entre os diferentes na sociedade (defesa das liberdades civis).

Nessa ideia, tem-se também a Convenção da Diversidade Cultural de 2005, que atribuiu a concepção de diversidade cultural no ordenamento jurídico. À vista disso, na opinião de Guilherme Rosa Varella, o termo "diversidade cultural" parece ser mais adequado ao princípio do que o termo "pluralismo cultural", uma vez que seria mais abrangente, ou pelo menos equiparado ao pluralismo. Para ele, a expressão diversidade significa o convívio entre diferentes expressões culturais, inclusive as diferenças entre uma mesma cultura e entre culturas diferentes (VARELLA, 2013, p. 101).

O referido princípio se encontra normatizados em diversos trechos da Carta Magna de 1988, entre eles estão: art. 215 (“O Estado garantirá a todos o pleno exercício dos direitos culturais..."); art. $215, \S 2^{\circ}$ (“a lei disporá sobre a fixação de datas comemorativas de alta significação para os diferentes segmentos étnicos nacionais”); art. 216, caput (“...à memória dos diferentes grupos formadores da sociedade brasileira") (grifo nosso).

No ordenamento infraconstitucional também pode ser encontrado esse princípio, patente nos artigos 22 e 39, da Lei ${ }^{\circ}$ 8.313/91 (essa lei restabelece os princípios da Lei $\mathrm{n}^{\circ}$ 7.505/86, que institui o Programa Nacional de Apoio à Cultura -Pronac), ipsis verbis:

Art. 22. Os projetos enquadrados nos objetivos desta lei não poderão ser objeto de apreciação subjetiva quanto ao seu valor artístico ou cultural.

Art. 39. Constitui crime, punível com a reclusão de dois a seis meses e multa de vinte por cento do valor do projeto, qualquer discriminação de natureza política que atente contra a liberdade de expressão, de atividade intelectual e artística, de consciência ou crença, no andamento dos projetos a que se refere esta Lei. (grifo nosso).

Evidencia-se que os artigos retromencionados vedam qualquer tipo de valoração (positivo ou negativa) sobre os projetos culturais avaliados para fins de recebimento de incentivo pelo Pronac, independentemente do seu segmento e conteúdo. 


\subsection{Princípio da Participação Popular}

O princípio da participação popular consiste no próprio povo ser protagonista da afirmação e proteção dos direitos culturais, cabendo a população deliberar e opinar sobre a política cultural firmada pelo Estado (CUNHA FILHO, 2004, p. 77). Essa deliberação popular pode ser realizada tanto pelos cidadãos, individualmente considerados, como por organizações civis.

A participação popular no setor cultural é garantida principalmente através de duas formas. A primeira é aquela realizada por meio de provocação do Poder Judiciário, no que diz respeito às ações judiciais, previstas no ordenamento constitucional, tais como a Ação Popular, a Ação Civil Pública e o Mandado de Segurança Coletivo (CUNHA FILHO, 2000, p. $50)$.

A segunda refere-se à participação popular direta no processo democrático, com a participação em conferências, fóruns, câmaras e colegiados setoriais relacionados à cultura nacional e a promoção de políticas públicas culturais (VARELLA, 2013, p. 102), bem como na participação de consultas públicas e formulação legislativa (princípio geral da democracia participativa e da transparência do poder público).

Um exemplo da participação popular direta na construção do texto normativo de lei infraconstitucional, é exposto a luz da Lei $\mathrm{n}^{\circ}$ 12.343/10 (Plano Nacional de Cultura), em que a população participou ativamente de sua produção. Apenas de forma exemplificativa, segue abaixo trechos do texto legal prevendo a participação da sociedade civil na elaboração, gestão e fiscalização de políticas públicas culturais, afixado no artigo $3^{\circ}$, inciso IX, da referida Lei: “Compete ao poder público, nos termos desta Lei: organizar instâncias consultivas e de participação da sociedade para contribuir na formulação e debater estratégias de execução das políticas públicas de cultura" (grifo nosso).

Retomando à legislação constitucional, o princípio da participação popular se faz presente nos artigos $216, \S 1^{\circ}$, e $5^{\circ}$, inciso LXXII, respectivamente a seguir:

Art. 216. $\S 1^{\circ} \mathrm{O}$ Poder Público, com a colaboração da comunidade, promoverá e protegerá o patrimônio cultural brasileiro, por meio 
de inventários, registros, vigilância, tombamento e desapropriação, e de outras formas de acautelamento e preservação.

Art. $5^{\circ}$. LXXIII - qualquer cidadão é parte legítima para propor ação popular que vise a anular ato lesivo ao patrimônio público ou de entidade de que o Estado participe, à moralidade administrativa, ao meio ambiente e ao patrimônio histórico e cultural [...]. (grifo nosso).

Demonstrada a presença do princípio da participação popular no ordenamento constitucional, procede-se à análise do princípio da atuação estatal como suporte logístico à cultura.

\subsection{Princípio da Atuação Estatal como Suporte Logístico}

O princípio da atuação estatal (referente à cultura) como suporte logístico dispõe que o Estado deverá dar suporte para que se tenha a realização das atividades culturais promovidas pelo povo. Isso significa que as expressões culturais não devem ser realizadas diretamente pelo Estado, muito menos que haja a sua interferência no exercício dos direitos culturais (liberdade de manifestação e expressão cultural) (CUNHA FILHO, 2004, p. 76).

O exercício da cultura e seu teor deverá ficar a encargo da população, uma vez a sociedade é livre e legítima para expor a cultura nacional, não podendo sofrer qualquer tipo de controle, restrição (censura) ou interferência. Esse corolário é garantido pela Constituição Federal de 1988 e tutelado pelo Estado Democrático de Direito.

Importante ressaltar que a atuação do Estado como Estado-mínimo na produção cultural, no sentido democrático (apartado do econômico-liberal), visa essencialmente garantir o pluralismo e diversidade cultural, tendo em vista que a cultura será produzido por aqueles inseridos na própria sociedade, e não uma imposição cultural pelo Poder Público.

No entanto, salienta-se alguns deveres da Administração Público determinados pela Lei Maior, em que o Estado deve promover certas diferenciações jurídicas a fim de atingir a igualdade material de certas expressões e manifestações culturais em situação de 
inferioridade, ao exemplo da proteção da cultura negra, indígena, popular e outros grupos de minorias, conforme preceitua o artigo $215, \S 1^{\circ}{ }^{5}$.

Por fim, pode ser constatado que os próprios verbos nucleares do caput, do artigo $215^{6}$, quais sejam "garantirá", “apoiará”, e “incentivará”, expressam a ideia de suporte e defensa das atividades culturais, mas não de agente realizador, que cabe a sociedade o exercício da prática cultural (CUNHA FILHO, 2000, p. 51).

\subsection{Princípio do Respeito à Memória Coletiva}

O princípio do respeito à memória coletiva consiste na tutela do acervo cultural da sociedade e sua memória coletiva (identidade e origens). Esse princípio tem por objetivo preservar os valores que identificam a sociedade (VARELLA, 2013, p. 103). Assim, os atores sociais e Poder Público "não podem negligenciar os valores da memória coletiva" (CUNHA FILHO, 2000, p. 51-52).

Segundo Guilherme Rosa Varella (2013, p. 103):

A proteção do patrimônio cultural, dos acervos, das datas simbólicas e da memória é garantida constitucionalmente (nos artigos 215 e 216 e parágrafos) com base nesse princípio, também chamado de princípio da solidariedade intergeracional por alguns autores ${ }^{7}$.

Mais especificamente, esse princípio é exposto à luz do artigo $216, \S 2^{\circ}$ e $\S 5^{\circ}$ da Constituição Federal de $1988^{8}$.

\subsection{Princípio da Universalidade}

\footnotetext{
${ }^{5}$ Art. 215. § $1^{\circ}$ : O Estado protegerá as manifestações das culturas populares, indígenas e afro-brasileiras, e das de outros grupos participantes do processo civilizatório nacional.

${ }^{6}$ Art. 215. Caput: O Estado garantirá a todos o pleno exercício dos direitos culturais e acesso às fontes da cultura nacional, e apoiará e incentivará a valorização e a difusão das manifestações culturais.

${ }^{7}$ Esses autores são: Ana Maria Marchesan, David Barbosa de Oliveira e Paulo de Souza Miranda.

${ }^{8}$ Art. 215 . \$ $2^{\circ}$ Cabem à administração pública, na forma da lei, a gestão da documentação governamental e as providências para franquear sua consulta a quantos dela necessitem; $\$ 5^{\circ}$ Ficam tombados todos os documentos e os sítios detentores de reminiscências históricas dos antigos quilombos.
} 
O princípio da universalidade visa garantir a possibilidade da prática dos direitos culturais por qualquer cidadão de forma indiscriminada, e o acesso indistinto aos benefícios do exercício desses direitos. Esse princípio garante que toda a sociedade usufrua da cultura de forma ativa (produzir e exercer a cultura) e passiva (usufruir dos benefícios das práticas culturais). Isso importa, portanto, que todos tenham o acesso à cultura e que não haja a exclusão de qualquer indivíduo por qualquer que seja o motivo.

Guilherme Rosa Varella (2013, p. 102) expõe de forma clara no que esse princípio se fundamenta:

O princípio da universalidade está ligado à ideia de acesso indistinto à cultura, de não exclusão dos indivíduos dos processos e benefícios culturais e de realização dos direitos culturais. Está relacionado ao princípio da pluralidade, porém enquanto este possui essência mais qualitativa (variedade de expressões e manifestações), a universalidade tem caráter mais quantitativo, como garantia de que a cultura será "acessada" de forma massiva e por todos, que são seus titulares, indistintamente. (VARELLA, 2013, p. 102) (grifo nosso).

Dessa forma, resta demonstrada a importância do reconhecimento dos princípios culturais. Conforme fora exposto acima, todos os princípios culturais convergem ao ideal de cumprimento dos preceitos constitucionais (princípios e garantias fundamentais) elencados pelo Estado Democrático de Direito, em suma, da relação entre o princípio da democracia e o direito fundamental à cultura.

\section{CONCLUSÃO}

Ante o exposto, tem-se que a Constituição Federal de 1988 estabeleceu uma extensa previsão normativa quanto aos direitos culturais, e encarregou-se de definir o conteúdo legal do termo cultura, exposto a luz do art. 216, em que estabelece um conceito amplo, de caráter universalista, que abrange tanto bens materiais, como bens imateriais, sob a figura do "patrimônio cultural brasileiro". Ainda, prevê o pleno exercícios dos direitos culturais (liberdade de criação, difusão, uso e gozo), o acesso às fontes de cultura, o incentivo e o fomento para a geração de valores e bens culturais, a fim de se atingir uma democracia cultural.

Por conseguinte, dada a importância dos direitos culturais, é patente que possuem a natureza de direitos fundamentais, tendo em vista que são essenciais para o exercício da plena 
cidadania e de uma vida digna, em consonância com os demais princípios e garantias fundamentais instituídos constitucionalmente, tais como o princípio da dignidade da pessoa humana, da liberdade, da igualdade, e os demais. Assim sendo, independentemente da interpretação adotada, stricto sensu ou lato sensu, os direitos culturais são direitos fundamentais, mesmo que estejam dispersos na Constituição Federal, e não expressos diretamente no Título II (Dos Direitos e Garantias Fundamentais).

Em harmonia com os preceitos constitucionais do Estado Democrático de Direito, os direitos culturais apresentam princípios próprios, implícito e explícitos, que alicerçam a legislação constitucional sobre cultura. De forma sucinta, são eles: o princípio do pluralismo cultural (diversidade cultural); o princípio da participação popular (povo como protagonista da cultura); o princípio da atuação estatal como suporte logístico (suporte do Estado na promoção da cultura); o princípio do respeito à memória coletiva (preservação dos valores sociais culturais); e por último, o princípio da universalidade (prática dos direitos culturais por todo e qualquer cidadão).

Dessa forma, conclui-se que a cultura nacional está presente em um rol extenso de valores, princípios e regras constitucionais, formando o que vem a ser chamado de ordenação constitucional da cultura, os quais são atribuídos o caráter de direitos fundamentais pela Constituição Federal de 1988, e, portanto, devem ser protegidos, garantidos e fomentados pelo Estado.

\section{REFERENCIAS}

ALEXY, Robert. Teoría de los derechos fundamentales. Madrid: Centro de Estudios Constitucionales, 1993.

BONAVIDES, Paulo. Curso de Direito Constitucional. 25ª ed. São Paulo: Malheiros, 2010.

BORGES, Letícia Menegassi. A Tutela Constitucional da Cultura no Brasil. In: XXV Encontro Nacional do CONPEDI, 2008, Brasília, Distrito Federal. Anais (on-line), Florianópolis: CONPEDI, 2016. Disponível em:

<http://www.conpedi.org.br/publicacoes/y0ii48h0/q5917p49/M469E1k36h26211o.pdf>. Acesso em: 28 mar. 2017.

BOTELHO, Isaura. Dimensões da Cultura e Políticas Públicas. São Paulo em Perspectiva, São Paulo, v. 15, n. 2, p.73-83, abr. 2001. Disponível em:

<http://www.scielo.br/pdf/spp/v15n2/8580.pdf>. Acesso em: 28 mar. 2017. 
CUNHA FILHO, Francisco Humberto. Cultura e Democracia na Constituição Federal de 1988: representação de interesses e sua aplicação ao Programa Nacional de Apoio à Cultura. Rio de Janeiro: Letra Legal, 2004.

Francisco Humberto. Cultura e democracia na Constituição Federal de 1988: representação de interesses e sua aplicação ao Programa Nacional de Apoio à Cultura. 2004. Tese (Doutorado). Faculdade de Direito do Recife, Universidade Federal de Pernambuco, Recife, 2004.

Francisco Humberto. Direitos Culturais como Direitos Fundamentais no Ordenamento Jurídico Brasileiro. Brasília: Brasília Jurídica, 2000.

, Francisco Humberto. Direitos Culturais no Brasil. Revista Observatório Itaú Cultural, São Paulo: Itaú Cultural, n. 11, p. 115-126, 2011. Disponível em: $<$ http://d3nv1jy4u7zmsc.cloudfront.net/wp-content/uploads/2014/03/RevistaObservat\%C3\%B3rio-11.pdf>. Acesso em: 03 abr. 2017.

DONDERS, Yvonne; LAAKSONEN, Annamari. Encontrando maneiras de medir a dimensão cultural nos direitos humanos e no desenvolvimento. Revista Observatório Itaú Cultural, São Paulo: Itaú Cultural, n. 11, p. 89-114, 2011. Disponível em: <http://d3nv1jy4u7zmsc.cloudfront.net/wp-content/uploads/2014/03/RevistaObservat\%C3\%B3rio-11.pdf>. Acesso em: 03 abr. 2017.

GUIMARÃES, Lilian. Sistema Estadual de Cultura é criado e reforça segmento no Amapá. Portal Governo do Estado do Amapá. [S.1.], 02 mar. 2017. Disponível em: $<$ http://www.amapa.gov.br/noticia/0303/sistema-estadual-de-cultura-e-criado-e-reforcasegmento-no-amapa>. Acesso em: 29 mar. 2017.

MELLO, Celso Antônio Bandeira de. Curso de Direito Administrativo. 25 a ed. São Paulo: Malheiros, 2008.

SALLES, Maria Beatriz Correa. A Lei da Cultura e a Cultura da Lei. 2013. Dissertação (Mestrado). Faculdade de Direito, Universidade São Paulo, São Paulo, 2014.

SANTOS, Felipe Monteiro dos. O Direito Fundamental à Cultura: mecanismos e políticas públicas para sua efetivação, tutela e democratização. 2011. Trabalho de Conclusão de Curso (Graduação). Pontifícia Universidade Católica do Rio De Janeiro, Rio de Janeiro, 2011.

SILVA, José Afonso da. Curso de Direito Constitucional Positivo. 17 $7^{\text {a }}$ ed. São Paulo: Malheiros, 1999. 2001. , José Afonso da. Ordenação Constitucional da Cultura. São Paulo: Malheiros,

Sistema Nacional de Cultura (SNC). Relatórios de Adesão ao SNC. [S.1], 19 abr. 2017. Disponível em: <http://www.cultura.gov.br/documents/1305219/1406425/2017.04.19++Situa\%C3\%A7\%C3\%A3o+dos+Estados+com+acordo.pdf/97a5ce8b-5fc8-4e48-bc7929b93b2812f0> Acesso em: 19 mai. 2017. 
TONET, Luciano; BORDONI, Jovina dÁvila. O Sistema de Cultura no Federalismo Americano e Brasileiro: contribuições norte-americanas para o federalismo cultural brasileiro. In: V Encontro Internacional do CONPEDI, 2016, Montevidéu, Uruguai. Anais (on-line), Florianópolis: CONPEDI, 2016. Disponível em:

<http://www.conpedi.org.br/publicacoes/9105o6b2/6114p753/EIVXOtF3Mr2391J7.pdf>. Acesso em: 29 mar. 2017.

VARELLA, Guilherme Rosa. Plano Nacional de Cultura: elaboração, desenvolvimento e condições de eficácia. 2013. Dissertação (Mestrado). Faculdade de Direito, Universidade São Paulo, São Paulo, 2013. 